\section{Ohio radiotelescope}

SIR - Your news item on the Ohio Wesleyan University-Ohio State University radiotelescope (Nature 10 February, p.455) was generally factual but made some inaccurate inferences.

First, you suggested that Ohio Wesleyan made an impulsive decision to sell the land "out from under" our neighbours at Ohio State. This is not true. Ohio State knew of our intention to look for potential buyers as early as 15 May 1981, when I sent a letter to former Ohio State president Harold Enarson. In addition, former OSU provost Ann Reynolds told me in January 1982 that her university was planning to cease operation of the telescope by 1984 . Based on those and subsequent communications, the Ohio Wesleyan Board of Trustees directed me to proceed with the sale.

Second, you seemed to imply that the sale demonstrates a disregard on our part for scientific inquiry. Again, this is not true. Although Ohio Wesleyan is an undergraduate institution, our faculty is actively involved in research. In the sciences, for example, nearly half of our faculty is funded by outside sources including the National Science Foundation, National Institutes of Health and industrial and private foundations. A member of our science faculty is currently in West Germany on a Fulbright scholarship. Furthermore, several of our faculty hold editorial and elected offices within their respective professional societies.

We believe that research is vital not only for the personal development and professional growth of our faculty, but that it also complements the educational experiences of our students. Evidence of the success of our commitment emerged in the fall when Ohio Wesleyan chemistry students captured the top three - and six of the top eleven - places in a national analytical chemistry competition in Pittsburgh. Biology students from Ohio Wesleyan University have presented research reports at national meetings and published their results in established journals.

The decision to sell the land on which the radiotelescope rests was based upon what we believed to be a mutual decision by ourselves and Ohio State. The sale was conducted following careful deliberation and should not be considered evidence that we are retreating from our traditional commitment to the sciences and specifically to scientific research. ThOMAS E. WEnzlau

Ohio Wesleyan University,

Delaware, Ohio, USA

\section{Millimetre wave telescope}

IN Sir Bernard Lovell's letter (Nature 21 April, p.650), Professor Smith's estimate in 1970 of the cost of constructing the $30-\mathrm{m}$ millimetre wave telescope was misprinted. It should read "greater than $£ 1$ million", not "greater than $£ 11$ million".

\section{Extinction by comet or asteroid}

SiR - In expressing his approval of Peter Smith's comments on rigid anticatastrophism in geological thinking ${ }^{1}$, Ken $\mathrm{Hs}^{2}{ }^{2}$ takes him to task nevertheless for attributing to Alvarez et al. ${ }^{3}$ the idea that the Cretaceous was terminated by a cometary impact. Professor Hsu can rightly claim priority in this respect and with good reason postulate less catastrophic $\left(10^{4} \mathrm{yr}\right)$ rather than instant extinction $\left(10^{\circ} \mathrm{yr}\right)$ (compare ref. 4).

The real issue at stake is rather more subtle than a straight distinction between Hsu's comet and Alvarez et al.'s asteroid. Thus, the proposal by $\mathrm{Hsu}^{5}$, following Urey $^{6}$, that extinctions are caused directly by comets may be excluded on general grounds because asteroidal impacts are both an order of magnitude more common and consistent as to rate with the incidence of major extinctions (five or six $10-\mathrm{km}$ missiles during the Phanerozoic). Alvarez et al., knowing this, suggested a meteoritic missile, also believing the asteroids in question (Apollos) derived from the asteroid belt. Wetherill ${ }^{7}$, however, had demonstrated that they are unlikely to be derived this way, so the cometary origin of Apollos proposed by Opik ${ }^{8}$ is to be preferred. On this hypothesis, Apollos are cometary asteroids, being comets deprived of their volatiles but not collisionally processed like meteorites. The Cretaceous period was thus most probably terminated by a cometary asteroid, as was indicated in our 1979 paper $^{9}$ (compare ref. 10).

In this paper elsewhere ${ }^{11,12}$, it has also been pointed out that no catastrophic theory of extinctions can be maintained if the "galactic" episodicity of geological phenomena is not predicted. We have shown that this happens in a natural way if the Oort cometary cloud feeding Apollos is actually dissipated and replenished each time the Sun passes through the galactic spiral arms.

Professor Hsu has clearly raised an important question but it is unlikely that evidence in the ground will readily distinguish between a comet or a cometary asteroid. The fundamental problem for theories of terrestrial catastrophism is therefore an astronomical one, whether spiral arms contains lots of comets.

S.V.M. CluBE W.M. NAPIER

Royal Observatory,

Edinburgh, UK

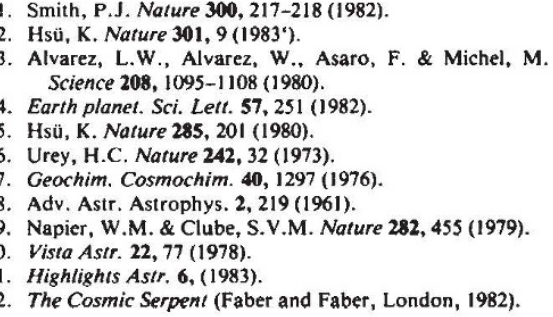

The Cosmic Serpent (Faber and Faber, London, 1982)

\section{Lake Mead moved}

SIR - In regard to the News \& Views article by R.D. Adams, "Incident at the Aswan Dam" (Nature 6 January, p.14), I would like to point out that Lake Mead, although on the Colorado River, is actually located in Nevada.

This of course presupposes that seismic activity did not translocate the lake from Colorado to Nevada.

DAVID R. WOODARD

Eisenhower Medical Center,

Rancho Mirage, California, USA

\section{Precocious Newton}

SIR - It must be assumed that Descartes reacted to Newton's "good luck" (Nature 14 April, p. 557) by turning in his grave. For when Descartes died, Newton was a child of seven.

Bath, UK

BASIL GREENSLADE

\section{Animal rights}

SIR - Speciesism is an ugly word and speciousness is not much better. Your notice of Professor Peter Singer's arguments for more humane treatment of laboratory animals (Nature 24 March, p.287) makes sad reading, combining selfrighteous superiority with the squalid device of guilt by association. You are sure that reviving of human volunteers as test organisms will not occur because "governments, societies and people would not allow such things to happen", as if counting the same people three times makes it true.

You suggest that Singer's "implied assertion that there is no sharp line to be drawn between people and other species of animals overlooks several simple truths". First among them you cite the example that populations of domestic animals are controlled "both as to number and to kind by people, not by the species concerned", as if that weakens, rather than helping to confirm, Singer's simple truth. Affluent and sophisticated Western societies can surely afford to look more carefully and more generously than our forebears at the many ethical and practical problems associated with human exploitation of animals, whether as pets, prey, the subjects of experiments or convenient devices for product quality control.

Please do not lend your weight to those already strong forces that press to close the watertight doors of self-interest as soon as a single voice obtains a wide public hearing on behalf of the great majority of the world's animals that manages its affairs without governments or societies and finds it prudent to treat people with a suspicion which your comments suggest is well merited.

Ottawa, Ontario, Canada
HUGH BOYD 